\title{
A ampliação do conceito de Património Cultural e o caso da Igreja de Nossa Senhora de Nazaré, de Morro Vermelho
}

\author{
Raphael Fabrino \\ FLUP/Doutoramento em Estudos do Patrimônio (DEP) \\ raphajhf@gmail.com
}

\section{Resumo}

O presente capítulo tem por objetivo refletir sobre a ampliação da noção de património cultural, sua consolidação no âmbito internacional e como o novo paradigma pode contribuir para a aferição de novos valores culturais, simbólicos e afetivos em relação a bens já protegidos legalmente em virtude de suas características materiais. A reflexão propõe-se revisitar e analisar a proteção legal e as práticas culturais associadas à imagem do Senhor dos Passos, da Igreja Matriz de Nossa Senhora de Nazaré, localizada no distrito de Morro Vermelho, em Caeté, Minas Gerais (Brasil).

Palavras Chave: Unesco; Patrimônio Cultural; Práticas Institucionais; Conceptualização

The amplification of Cultural Heritage concept and the study case of the Church of Nossa Senhora da Nazaré from Morro Vermelho

\begin{abstract}
This chapter aims to reflect on the amplification of cultural heritage concept, its consolidation at the international level and how the new paradigm can contribute to the assessment of new cultural, symbolic and affective values in relation to goods already legally protected due to its material characteristics. The reflection proposes to revisit and analyse the legal protection and cultural practices associated with of Senhor dos Passos image, from the Main Church of Nossa Senhora de Nazaré, located in the district of Morro Vermelho, in Caeté, Minas Gerais (Brazil).

Keywords: Unesco; Cultural Heritage; Institutional Practices; Conceptualization
\end{abstract}


Fabrino, Raphael (2020). A ampliação do conceito de Patrimonio Cultural e o caso da Igreja de Nossa Senhora de Nazaré, de Morro Vermelho. In Alice Duarte (ed.), Seminários DEP/FLUP vol. 1. Porto: Universidade do Porto, Faculdade de Letras/DCTP, 192-215. https://doi.org/10.21747/9789898969682/seminariosv1a9

\section{Introdução}

O presente capítulo tem por objetivo refletir sobre as novas leituras e abordagens acerca do património cultural vislumbradas a partir das premissas da Convenção da Unesco para a Salvaguarda do Património Cultural Imaterial, de 2003. Nesse sentido, entende-se que mais do que identificar, valorizar e salvaguardar outras formas, manifestações e expressões culturais, essa Convenção lança um olhar renovado acerca do campo patrimonial, o que vai permitir agregar novas narrativas e valores simbólicos a bens já legalmente protegidos sobretudo por suas características históricas, artísticas ou naturais.

Portanto, é necessário entender a referida Convenção de 2003 como um instrumento de proteção complementar aos demais meios existentes que permite pensar o património cultural e as práticas da sua preservação de forma integral, e não como um conjunto de regras autónomas e independentes que criam novos patrimônios a partir do momento da sua aplicação. A fim de observar como esta nova visão do património pode colaborar para a aferição de novos valores em bens culturais já protegidos, esta reflexão buscará analisar a proteção legal e os estudos referentes à Igreja Matriz de Nossa Senhora de Nazaré, localizada em Morro Vermelho, distrito do município de Caeté (Minas Gerais, Brasil) e à imagem do Senhor dos Passos pertencente ao seu acervo.

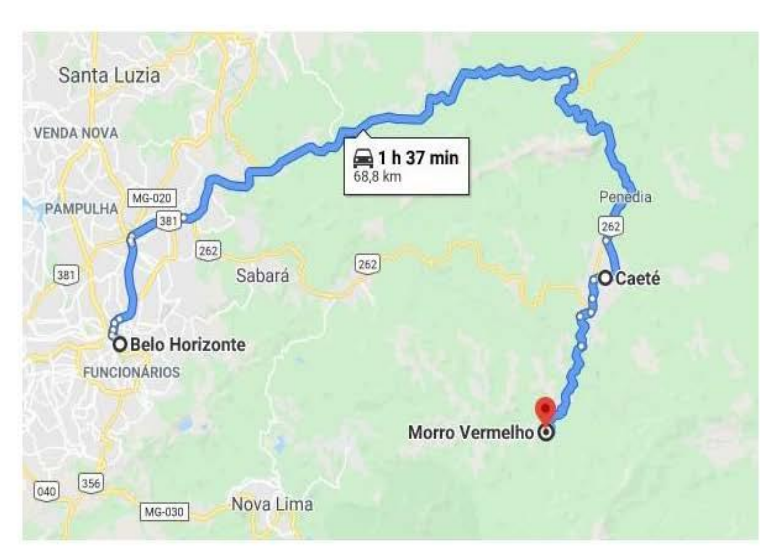

Fig 1 Mapa indicando distância de Belo Horizonte Vermelho; Fonte Google Maps, 2020;

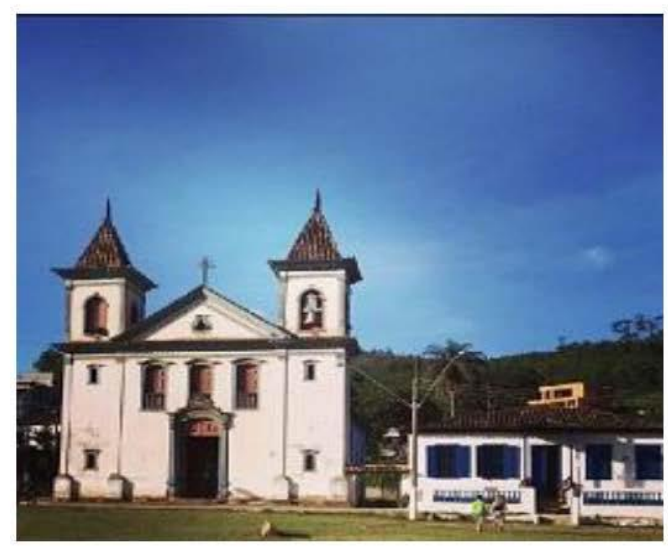

Fig. 2 - Igreja Matriz de N. S. de Nazaré; Fonte-Arquivo Central do IPHAN) 
Fabrino, Raphael (2020). A ampliação do conceito de Patrimonio Cultural e o caso da Igreja de Nossa Senhora de Nazaré, de Morro Vermelho. In Alice Duarte (ed.), Seminários DEP/FLUP vol. 1. Porto: Universidade do Porto, Faculdade de Letras/DCTP, 192-215. https://doi.org/10.21747/9789898969682/seminariosv1a9

Sobre estes bens recaem uma série de medidas de preservação, visando salvaguardar os seus mais diversos aspetos culturais. No entanto, tais medidas foram aplicadas em diferentes momentos da história e pelas três esferas de intervenção estatal existentes no Brasil. Cada uma dessas ações de proteção carrega as premissas legais e o pensamento acerca do património cultural que marcou determinada época. A Igreja de Nossa Senhora de Nazaré e o seu acervo foram tombados e inscritos no Livro de Belas Artes, pelo Instituto do Patrimônio Histórico e Artístico Nacional (IPHAN), em 1952, por força do Decreto-Lei $n^{\circ} 25$ de 1937. A Cavalhada de Nossa Senhora de Nazaré foi registrada no Livro de Celebrações do município de Caeté, em 2009, atualmente sob os efeitos da Lei Municipal ํo 2.677, de 2011. O Ritual do Banho de Cachaça da imagem do Senhor dos Passos de Morro Vermelho foi inventariado pelo Instituto Estadual do Patrimônio Histórico e Artístico (IEPHA) de Minas Gerais, no ano de 2013.

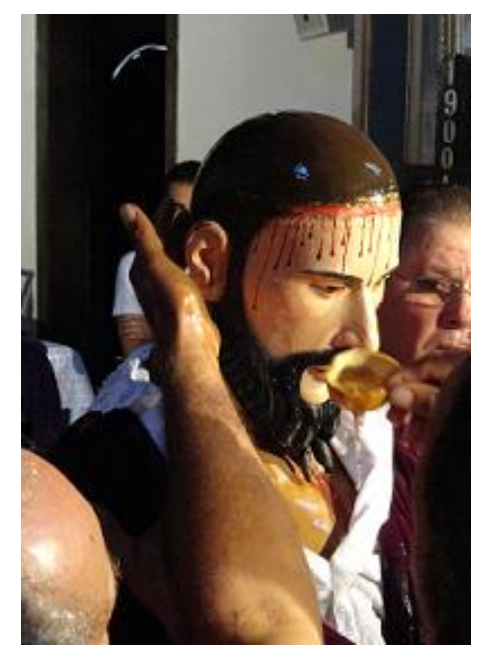

Fig 3 - Ritual do Banho de Cachaça sobre a imagem do Senhor dos Passos da Igreja de N. S. da Nazaré

A sobreposição destes diversos mecanismos de proteção, sem a devida apreciação das suas implicações legais, somada à ausência de uma visão integral da noção de património, pode desdobrar-se em conflitos técnicos e conceituais sobre o que preservar e como. Nesse sentido, a análise do caso da Igreja de Nossa Senhora de Nazaré e da sua imagem do Senhor dos Passos pode vir a ser esclarecedora para se compreender a necessidade de uma visão mais integrada e atualizada do património cultural na contemporaneidade e da própria Convenção de 2003. 
Fabrino, Raphael (2020). A ampliação do conceito de Patrimonio Cultural e o caso da Igreja de Nossa Senhora de Nazaré, de Morro Vermelho. In Alice Duarte (ed.), Seminários DEP/FLUP vol. 1. Porto: Universidade do Porto, Faculdade de Letras/DCTP, 192-215. https://doi.org/10.21747/9789898969682/seminariosv1a9

\section{A ampliação do conceito de património no âmbito internacional}

Se o conceito de património cultural se começa a formar em França, ainda na virada do século XVIII para o XIX, as ideias que permitiram o seu entendimento atual começam a surgir dentro da Unesco somente nos anos de 1960. Mas é apenas a partir da década de 1980 que surgem os primeiros marcos internacionais que permitiram reformular a ideia de património cultural. Em 1982, durante a Conferência Mundial sobre as Políticas Culturais, do Conselho Internacional de Monumentos e Sítios (ICOMOS), no México, foi lançada a Declaração do México, de importância vital. Segundo a antropóloga Alice Duarte (2010: p. 48), a noção contemporânea de patrimônio cultural, que inclui a dimensão imaterial ou intangível, começa a tomar forma com este documento. Nele, uma nova conceituação mais próxima da noção de cultura associava elementos espirituais e materiais, intelectuais e afetivos como estando necessariamente presentes em todos os modos de vida, sistemas de valores, tradições e crenças, assim como em qualquer obra erudita e popular, célebre ou anónima. Essa perspectiva indicava a possibilidade de reconhecimento como bens patrimoniais a novas e distintas manifestações e expressões culturais que, até então, estavam excluídas do sistema de proteção do Património Mundial devido aos seus parámetros de eleição, que se pautavam em exclusivo pelas dimensões materiais e atendendo a critérios como originalidade, autenticidade, monumentalidade e "valor excepcional universal". Dentro da Unesco, era já antiga uma reinvindicação dos países da América Latina, África e Ásia sobre a revisão dos critérios adotados para a eleição do Património Mundial, sem o que grande parte dos seus bens patrimoniais ficavam excluidos.

A perspectiva de um novo instrumento para identificar e salvaguardar outras formas de manifestações e expressões do patrimônio cultural foi desenvolvida ao longo da década de 1980 e, em particular, no ano de 1989, quando a Conferência Geral da Unesco adotou a Recomendação sobre a Salvaguarda da Cultura Tradicional e do Folclore. Esta Recomendação é considerada uma referência no que tange à mudança de percepção sobre o património cultural dentro da instituição, uma vez que destaca o valor cultural das relações sociais e simbólicas, da diversidade e da percepção dos diferentes sujeitos sobre seus bens e práticas sociais. Esta perspectiva não mais se 
Fabrino, Raphael (2020). A ampliação do conceito de Patrimonio Cultural e o caso da Igreja de Nossa Senhora de Nazaré, de Morro Vermelho. In Alice Duarte (ed.), Seminários DEP/FLUP vol. 1. Porto: Universidade do Porto, Faculdade de Letras/DCTP, p.192-215. https://doi.org/10.21747/9789898969682/seminariosv1a9

limitava apenas aos objetos, técnicas ou produção material, mas passava a incluir todo o conjunto de traços distintivos que caracterizam um grupo social, sejam eles espirituais, materiais, intelectuais ou afetivos.

Já na decada seguinte, em 1993, a Unesco lança o Programa de incentivo à transmissão do conhecimento, intitulado Sistema de Tesouros Humanos Vivos. No ano seguinte, no Japão, é elaborada a Carta de Nara que questiona a visão ocidental de preservação, assente nos conceitos de autenticidade e originalidade. Um ponto de destaque deste documento diz respeito à abrangência e à visão integrada do patrimônio cultural aí subscrito: "todas as culturas e todas as sociedades estão enraizadas em formas e em meios particulares de expressão tangível e intangível que constituem o seu património" (Carta de Nara, 1994: p. 2). Em 1997 assiste-se ainda ao lançamento do Programa da Unesco para a Proclamação das Obras-Primas do Património Oral e Imaterial da Humanidade, cujas três edições (2001, 2003 e 2005) assegurm a proteção de cerca de 90 obras-primas, as quais transitarão posteriormente para a alçada da Convenção para Salvaguarda do Património Cultural Imaterial.

A consolidação destas novas formas de se pensar e entender o património cultural servirão como principal referência para a formulação das políticas de preservação na década seguinte. Em 2001, por meio da Declaração Universal sobre a Diversidade Cultural, a Unesco afirma o caráter plural da cultura, que pode assumir diversas e distintas formas ao longo do tempo e do espaço. É sob este espírito que, dois anos mais tarde, em 2003, é lançada a Convenção para Salvaguarda do Patrimonio Cultural Imaterial.

Esta Convenção, logo no seu Preâmbulo, conceitua uma perspectiva integrada sobre o património cultural, onde se destaca "a profunda interdependência entre o património cultural imaterial e o património cultural material e natural". Nesse sentido, é correto afirmar que o documento sugere que as práticas e instrumentos de salvaguarda devem ser complementares, capazes de compreender as manifestações e expressões da cultura em toda a sua riqueza e abrangência. Vale destacar a associação promovida entre "as práticas, representações, expressões, conhecimentos e competências" e os bens materiais que Ihe dão suporte, como os "instrumentos, objetos, artefatos e espaços culturais que lhes estão associados". Esse novo 
Fabrino, Raphael (2020). A ampliação do conceito de Patrimonio Cultural e o caso da Igreja de Nossa Senhora de Nazaré, de Morro Vermelho. In Alice Duarte (ed.), Seminários DEP/FLUP vol. 1. Porto: Universidade do Porto, Faculdade de Letras/DCTP, 192-215. https://doi.org/10.21747/9789898969682/seminariosv1a9

instrumento legislativo permitiu que, até o fim do ano de 2019, fossem registadas como Património Cultural Imaterial da humanidade 549 manifestações e expressões culturais, pertencentes a 127 países.

Para além de possibilitar outras formas de reconhecimento e de proteção, ao ampliar a noção do que pode ser considerado património cultural e complementar as normativas já existentes, a Convenção de 2003 também promove um novo entendimento sobre os bens protegidos até então - o que permite a identificação de novos elementos e expressões culturais em bens até então apenas valorizados pelas suas dimensões materiais, históricas ou artísticas.

Apesar da consolidação inequívoca de novas formas de se pensar o património cultural a partir da Convenção de 2003, e do seu sentido mais integrador, os mecanismos de proteção e salvaguarda do Património Cultural Imaterial foram internalizados pelas instituições nacionais brasileiras, e também replicados nas legislações estaduais e municipais do país, de forma desarticulada, sem se pensar na conciliação possível com as políticas de proteção já existentes. No caso do Brasil, a legislação nacional que institui o Registro de Bens Culturais de Natureza Imaterial ocorre três anos antes da Convenção de 2003, por meio de Decreto $n^{\circ} 3551$ de 2000. Como efeito dessa desarticulação, e de modo semelhante ao ocorrido na generalidade dos outros países e instituições, as ações de pesquisa e estudo envolvendo o Património Cultural Imaterial consolidaram-se através de meios distintos do dito património "tradicional", com diferentes mecanismos legais de proteção, equipas de trabalho, disciplinas e orçamentos. No Brasil, essa situação é ainda multiplicada e complexificada pela existência simultânea das legislações estaduais e municipais que, em geral, também operam dentro da dicotomia material e imaterial quanto aos meios de salvaguardar do seu património cultural.

\section{A igreja de Nossa Senhora de Nazaré, de Morro Vermelho identificada como Património Nacional em 1950}

A cidade de Caeté, antiga Vila Nova da Rainha, fundada em 1714, localiza-se na região metropolitana de Belo Horizonte, a cerca de $70 \mathrm{~km}$ da capital mineira. A cidade, assim como o seu distrito, Morro Vermelho, são considerados núcleos fundadores que 
Fabrino, Raphael (2020). A ampliação do conceito de Patrimonio Cultural e o caso da Igreja de Nossa Senhora de Nazaré, de Morro Vermelho. In Alice Duarte (ed.), Seminários DEP/FLUP vol. 1. Porto: Universidade do Porto, Faculdade de Letras/DCTP, 192-215. https://doi.org/10.21747/9789898969682/seminariosv1a9

remetem aos primórdios da ocupação do território mineiro. A região foi palco de alguns conflitos na Guerra dos Emboabas, travada ente 1707 e 1709, entre os bandeirantes Paulistas e os Forasteiros vindos de Portugal e de outras partes do Brasil, motivada pelas disputas de exclusividade da exploração aurífera em Minas Gerais. O passado colonial legou à região um importante conjunto histórico e arquitetónico que já nos primeiros anos de atividade do IPHAN, se tornou alvo de proteção como património cultural do Brasil.

O distrito de Morro Vermelho fica a cerca de oito 8 quilómetros de Caeté, encravado na serra homónima e antigo local de extração de ouro das minas de ViraCopos. O distrito ainda preserva um importante conjunto arquitetónico colonial com destaque para o casario setecentista e a Igreja Matriz de Nossa Senhora de Nazaré, tombada como Património Nacional pelo processo $\mathrm{n}^{\circ} 0397-\mathrm{T}$, a 9 de maio de 1950, e inscrita no Livro de Belas Artes, em 1952. No sítio da internet do IPHAN aparece uma caracterização da Igreja com destaque para os seus elementos arquitetónicos e artísticos:

Descrição: Igreja setecentista com fachada simétrica constituída por portada e três janelas frontão triangular. As torres têm cobertura de telhado em quatro águas. Internamente a nave apresenta piso em tabuado largo e forro em tabuado liso, em abóbada facetada com pintura perspectivista, provavelmente de meados a fins do século XIX. A capela-mor, de maior interesse, possui forro em abóbada de berço com pintura perspectivista composta nas laterais por muro-parapeito contínuo, e no quadro central o tema da Assunção da Virgem. Atrás do muro-parapeito encontramse as figuras dos doutores da Igreja: São Gregório, São Jerônimo, Santo Ambrósio e Santo Agostinho ${ }^{1}$.

O processo de tombamento $n^{\circ}$ 0397-T, é formado por documentação administrativa com os encaminhamentos internos e comunicados externos, informando sobre a proteção do bem, num total de nove páginas. O primeiro documento é a carta de um morador de Morro Vermelho chamado Raimundo Xavier, datada de 16 de junho de 1949 e endereçada ao então presidente do IPHAN, Rodrigo de Melo Franco de Andrade. Nela, o morador informa que alguns técnicos do património andaram pela região e ficaram de retornar com recursos para o restauro da igreja, porém, os

\footnotetext{
${ }^{1}$ http://portal.iphan.gov.br/ans.net/tema consulta.asp?Linha=tc belas.gif\&Cod=1283 Acesso em: 03/05/2019
} 
Fabrino, Raphael (2020). A ampliação do conceito de Patrimonio Cultural e o caso da Igreja de Nossa Senhora de Nazaré, de Morro Vermelho. In Alice Duarte (ed.), Seminários DEP/FLUP vol. 1. Porto: Universidade do Porto, Faculdade de Letras/DCTP, 192-215. https://doi.org/10.21747/9789898969682/seminariosv1a9

moradores não tinham tido mais notícias. Relatando a precariedade do templo, pede providências:

Há tempos estiveram aqui em Morro Vermelho uns senhores do património histórico visitando nossas igrejas e nos informaram que logo depois seria feito o tombo da nossa matriz, saindo em seguida a verba para sua reconstrução. Já fazem mais ou menos uns 4 anos, depois não apareceu mais ninguém. Nesse período a igreja foi estragando cada vez mais chegando a ficar agora - com as chuvas desse ano - cada vez mais ameaçada, principalmente o telhado. (Processo IPHAN no 0397-T, 1950, p.1)

Pedimos-Ihe a fineza de se interessar pelo nosso caso e nos ajudar no que the for possivel pois nosso lugar é pobre demais e é para nós bastante consternador ver desmoronar aquilo que temos de melhor e mais caro em nossos corações. (Processo IPHAN no 0397-T, 1950:p. 2)

Na sequência dos documentos encontra-se outra carta, agora emitida pelo diretor de Estudos de Tombamento, indicando a motivação para a proteção da Igreja pela "necessidade de preservar convenientemente a Igreja Matriz de Nossa Senhora de Nazaré pelo seu valor artístico". Em seguida, aparece um telegrama de Melo Franco, o então presidente do IPHAN, solicitando ao chefe do 30 distrito do IPHAN de Minas Gerais, Sylvio de Vasconcellos, que comunique ao arcebispo de Belo Horizonte, D. Cabral, a proteção da referida Igreja. Um novo telegrama escrito por Melo Franco é enviado no ano seguinte ao diretor da regional, solicitando a manifestação do arcebispo quanto ao pedido anterior, a fim de encerrar o processo de tombamento, juntamente com outros assuntos de interesse. O processo encerra-se com um telegrama enviado por Sylvio de Vasconcelos ao presidente do IPHAN, informando do encontro com o arcebispo e confirmando a sua concordância em relação à proteção da Igreja de Morro Vermelho.

Nesse período, os discursos e conceitos de preservação vigentes entendiam a proteção do patrimônio cultural como um ato eminentemente técnico-administrativo, sem necessidade de justificativas ou debates, com a valorização exclusiva de traços arquitetónicos, estéticos e históricos. Também é importante ressaltar que o tombamento de uma igreja como Património Nacional inclui a proteção de todo o acervo presente no templo à data de conclusão do processo, de acordo com a Resolução do Conselho Consultivo da SPHAN, de 13 de agosto de 1985. Deste modo, os bens móveis e integrados presentes na Igreja também passam a ser regidos por um sistema especial de proteção do património cultural brasileiro, assente nas premissas do 
Fabrino, Raphael (2020). A ampliação do conceito de Patrimonio Cultural e o caso da Igreja de Nossa Senhora de Nazaré, de Morro Vermelho. In Alice Duarte (ed.), Seminários DEP/FLUP vol. 1. Porto: Universidade do Porto, Faculdade de Letras/DCTP, 192-215. https://doi.org/10.21747/9789898969682/seminariosv1a9

Decreto-Lei $n^{\circ} 25$ de 1937. Para efeito deste estudo convém destacar o artigo 17 do referido Decreto:

Artigo 17-As coisas tombadas não poderão, em caso nenhum, ser destruídas, demolidas ou mutiladas, nem, sem prévia autorização especial do Serviço do Patrimônio Histórico e Artístico Nacional, ser reparadas, pintadas ou restauradas, sob pena de multa de cinquenta por cento do dano causado.

No Arquivo Central do IPHAN é possível consultar o inventário de bens móveis e integrados da Igreja, de onde destacamos a ficha da imagem do Senhor dos Passos. O inventário, realizado em junho de 1987, possui informações relacionadas com os dados cadastrais, levantamento físico da imagem, registo fotográfico, descrição pormenorizada, datação como sendo do séc. XVIII de fabrico popular, análise iconográfica, estilística e da técnica construtiva. Não foram localizados dados históricos específicos sobre a peça. A descrição chama ainda a atenção para o seu estado de conservação: "lacunas irreversíveis no suporte dos dedos e das mãos. Repintura. Perda do suporte devido ao ressecamento. Perfurações circulares, provavelmente provocadas por pregos. Abrasões e desgastes. Sujidades". Ao analisarmos este conjunto de informações sobre a Igreja e a sua imagem do Senhor dos Passos é possível perceber um sistema de valores patrimoniais ligados estritamente aos seus aspectos históricos, construtivos e artísticos.

Ao revisitar estes bens sob as premissas atuais da definição do património cultural é possível reconhecer uma série de outros valores e elementos simbólicos e culturais passíveis de identificação e proteção. Nesse sentido, uma visão mais antropológica da noção de cultura e o alargamento da noção de património cultural, propiciado pela legislação nacional e internacional, possibilitam reconhecer e valorar outros importantes aspetos em um bem cultural. Até então, esses bens recebiam um tratamento quase museológico, mas cuja preocupação consistia na valorização dos seus traços históricos e artísticos e na preservação de sua materialidade. Cabe lembrar ainda que, apesar da concepção do tratamento até então aplicado, alguns bens do património cultural ainda se configuram como em uso, ou seja, servindo a função para a qual foram concebidos. O recurso a um tratamento patrimonial de base museológica num bem cultural que ainda se apresenta em uso, principalmente se de cunho devocional, pode 
Fabrino, Raphael (2020). A ampliação do conceito de Patrimonio Cultural e o caso da Igreja de Nossa Senhora de Nazaré, de Morro Vermelho. In Alice Duarte (ed.), Seminários DEP/FLUP vol. 1. Porto: Universidade do Porto, Faculdade de Letras/DCTP, 192-215. https://doi.org/10.21747/9789898969682/seminariosv1a9

ocasionar sérias consequências e até rupturas em relação à continuidade das práticas a ele associadas.

\section{A igreja de Nossa Senhora de Nazaré, de Morro Vermelho: uso e práticas associadas}

\subsection{A Cavalhada de Nossa Senhora de Nazaré}

Ao revisitarmos a Igreja de Nossa Senhora de Nazaré de Morro Vermelho guiados pelas premissas do conceito integrado de património cultural e da noção antropológica de cultura - privilegiando, portanto, as relações sociais e simbólicas em detrimento dos objetos, construções em si ou técnicas - chama a atenção aspectos culturais fortemente associados a este templo, com destaque para a Cavalhada de Nossa Senhora de Nazaré. A reportagem publicada na Revista Círios, de 2007, informa que a festividade é uma das mais antigas festas religiosas brasileiras celebrada de modo ininterrupto:

A festa de Nossa Senhora de Nazaré, tradição de 300 anos em Morro Vermelho, Minas Gerais, começa ao meio dia do dia 30 de agosto, com repique de sinos e fogos de artifício anunciando aos moradores o início das homenagens à Virgem de Nazaré. À noite começa a novena, repetida diariamente. (...) Em 6 de setembro, ao final da tarde, a bandeira de Nossa Senhora de Nazaré percorre as ruas de Caeté, acompanhada por mais de 200 cavaleiros, que a conduzem até Morro Vermelho, onde é recebida, à noite, sob aplausos. No dia 7 de setembro os moradores são acordados às $4 \mathrm{~h}$ com alvorada, fogos e repique de sinos. São celebradas missas pelos festeiros, mordomos e cavaleiros, preparando-se para a Cavalhada à noite, após a novena. Em 8 de setembro, natividade de Nossa Senhora, há missa cantada em latim a quatro vozes, acompanhada de orquestra, à noite é realizada procissão pelas ruas enfeitadas. A chegada da imagem à matriz é transformada em apoteose, sendo a festa encerrada com Te Deum, em agradecimento a Deus pelo sucesso da Festa. (Revista Círios, 2007: 60)

A reportagem data o início das festividades em Morro vermelho no ano de 1704 e revela uma peculiaridade da sua encenação na região:

Apesar de enfocar a luta entre mouros e cristãos, a cavalhada de Morro Vermelho representa, na verdade, o final da guerra, culminando com a vitória dos cristãos, a conversão e o pacto de aliança. É o final da luta contra os muçulmanos, que aceitam a fé cristã. Para selar a paz, depois de quase 800 anos de guerra, 12 cavaleiros cristãos e 12 mouros conduzem a bandeira de Nazaré até à praça enfeitada, onde são recebidos por fogos de artifício, repique de sino, banda de música e aplausos da multidão. A cavalhada começa com o imperador mouro saudando com embaixadas a Bandeira, recebida do embaixador cristão que também a venera. Logo depois, os mouros hasteiam a bandeira de Nazaré em seu reino, simbolizando que adotaram a 
Fabrino, Raphael (2020). A ampliação do conceito de Patrimonio Cultural e o caso da Igreja de Nossa Senhora de Nazaré, de Morro Vermelho. In Alice Duarte (ed.), Seminários DEP/FLUP vol. 1. Porto: Universidade do Porto, Faculdade de Letras/DCTP, 192-215. https://doi.org/10.21747/9789898969682/seminariosv1a9

fé cristã. Para selar a paz, os embaixadores dão novas embaixadas. Cristãos e mouros entrelaçam fitas no mastro, amarrando o compromisso de fé aos pés de Nossa Senhora. Unidos, os cavaleiros fazem uma série de evoluções. Encenam um 8 (união de dois povos), uma meia lua (inicio da amizade crescente), assistem a um espetáculo pirotécnico (queima dos deuses pagãos) e fazem novas evoluções. (...) No dia 7 de setembro, após a novena, às 21 horas, na praça toda engalanada e cercada de cordas e bandeirolas, o público aguarda ansioso o início da cavalhada. Os festeiros iniciam, então, a "chamada geral" da cavalhada, através de salvas de fogos de artifício, aguardando-se uma resposta dos cavaleiros do outro local. Tão logo se acomodam nas selas, os cavaleiros respondem com outra salva de fogos de artifício, iniciando o desfile até à praça, sob intensa queixa de fogos. À frente vêm os dois embaixadores, com bengalas iluminadas, seguidos por dois cavaleiros com a bandeira e os demais pares. Ao chegar na praça, os 14 cavaleiros são recebidos por fogos de artifício, repique de sino, banda de música e aplausos da multidão. Logo depois, os dois embaixadores, cercados pelos cavaleiros, iniciam a movimentação diante da bandeira. Com embaixadas, o líder dos mouros declara aceitar o estandarte de Nazaré. Seguemse as embaixadas do cristão, que pede ao mouro para erguer a Bandeira em seu reino, como prova de adoção da fé cristã. As duas partes se unem e se retiram da praça. A comunidade inicia então o levantamento de um mastro de mais de 20 metros, com auxílio de tesouras de madeira. Os embaixadores mouro e cristão voltam à praça para novas embaixadas diante do mastro. Logo após, mouros e cristãos entrelaçam fitas em redor do mastro, simbolizando a união dos povos. Os doze pares voltam à praça para fazer diversas evoluções, simbolizando um "8", uma meia lua e outros movimentos. Finalmente, eles fazem a despedida, agitando lenços brancos para a multidão. Todas as evoluções de mouros e cristãos são acompanhadas por músicas típicas executadas pela Corporação Musical Santa Cecília, banda centenária de Morro Vermelho. Durante os dias da Festa de Nossa Senhora de Nazaré, todo o interior da Igreja é também ornamentado para receber romeiros de todas as partes. Especialmente a imagem da padroeira é ricamente adornada com flores para ser venerada pelos fiéis. (Revista Círios, 2007: 61, 62 e 63)

Outro ponto significativo desta celebração refere-se à Bandeira de Nossa Senhora de Nazaré que, durante o período das novenas, de 30 de agosto a 6 de setembro, percorre diversas residências da cidade de Caeté, abençoando os seus moradores. Em seu estudo relacionado com a "devoção a Nossa Senhora de Nazaré", a pesquisadora Renata Araújo (2004) apresenta uma série de entrevistas com os moradores que ilustram o processo e transmissão do conhecimento intergeracional relacionado com as festividades. Na transcrição do relato de um dos participantes da comunidade, identificado como "Biló", é possível observar esse processo:

Nasceu, assim, com os pais. Papai mexia, eu acompanhando ele, a gente... Ele ia lá pegava um trem e a gente ia atrás. Então, assim, a gente foi tomando aquela fé, aquele trem, que junto com ele, mexendo, depois a gente assumiu... vai assumindo a responsabilidade de festa. A gente já foi ficando, assim, com mais fé e, assim, nós vão tendo as coisa igual nós tá hoje. Acabou que a gente, agora, tá tomando até responsabilidade de festa. (Araújo, 2004: 33) 
Fabrino, Raphael (2020). A ampliação do conceito de Patrimonio Cultural e o caso da Igreja de Nossa Senhora de Nazaré, de Morro Vermelho. In Alice Duarte (ed.), Seminários DEP/FLUP vol. 1. Porto: Universidade do Porto, Faculdade de Letras/DCTP, p.192-215. https://doi.org/10.21747/9789898969682/seminariosv1a9

Esse processo de transmissão de conhecimento intergeracional também pode ser observado no relato de Dona Beatriz:

Ah, isso, desde pequena. Porque não tem, quer dizer, aqui foi sempre muito pequeno. E também isso foi em casa. Tudo vem de casa mesmo; num tem outra explicação não. Lá em casa toda vida foi assim: tudo quanto há era Nossa Senhora de Nazaré. Num tinha mesmo... É que tudo quanto há era "Nossa Senhora de Nazaré que ajudava", "Nossa Senhora de Nazaré que protege", é "Nossa Senhora de Nazaré que ajuda"; e também a gente cresceu num ambiente, assim, de muita oração. O que papai e mamãe puderam colocar em mim de bom, eles colocaram; [...] Depois, quer dizer, o que foi...quer dizer, eu tive a graça de ter tido papai e mamãe que me incutiram, apesar da simplicidade, apesar de num ter... mas tinha perto. Eles puderam passar isso pra mim; quer dizer que, então, num tem como... num tem como 'cê... 'Cê viveu ali, raiz mesmo, é negócio que foi incutido na gente. (Araújo e Mahfoud, 2004: 38)

Apesar de ser descrita como uma festa "tradicional" que mantém suas "características originais" é possível observar a utilização de elementos da festividade noutros contextos, como a visita da bandeira de Nossa Senhora à escola Municipal Dr. João Pinheiro, em comemoração do seu centenário, em 2008. Ou ainda, a visita da bandeira ao Santuário da Serra da Piedade, em virtude da programação de seu grande Jubileu. Outra reportagem da Revista Círios, do ano de 2011, informa sobre a participação especial naquele ano do Congado de Santo Antônio do Deschamps. Também nessa reportagem, é descrito um elemento distintivo das comemorações em Morro Vermelho, na tarde do dia 7 de setembro:

À tarde as pessoas assistiram ao desfile dos mascarados (chamados de bando), personagens que expulsam os males das casas e das ruas para a tradicional cavalhada à noite. Eles também saem pelas ruas durante todos os domingos do mês de agosto, assustando a criançada, que os acompanham até o fim do trajeto. $O$ ritual acontece com pessoas batendo caixas e tocando sanfonas. (Revista Círios, 2011: 56).

A adoção do conceito antropológico de cultura pressupõe o reconhecimento do seu caráter dinâmico, aceitando os novos usos, valores e práticas incorporados à festividade como características fundamentais para que esta permaneça viva. A antropóloga Alice Duarte (2010: p. 51) chama a atenção ainda para o aspecto potencialmente mutável das manifestações patrimoniais como contendo a possibilidade de integração de novas interpretações e o estabelecimento de conexões criativas com o passado. Outras práticas como a elaboração de tapetes com serradura no adro da Igreja, para a passagem da procissão e a decoração com flores, arcadas e bandeirolas de distintas cores por todo o seu percurso e locais da festividade também são parte desta 
Fabrino, Raphael (2020). A ampliação do conceito de Patrimonio Cultural e o caso da Igreja de Nossa Senhora de Nazaré, de Morro Vermelho. In Alice Duarte (ed.), Seminários DEP/FLUP vol. 1. Porto: Universidade do Porto, Faculdade de Letras/DCTP, 192-215. https://doi.org/10.21747/9789898969682/seminariosv1a9

celebração em Morro Vermelho. Um ponto significativo da celebração é a farta distribuição de bolos, doces e salgados, feitos pelos moradores para comemorar o "aniversário de Nossa Senhora", após a missa do dia 8 de setembro. Nessa ocasião, ao fim da missa é cantado o "Parabéns" a Nossa Senhora e as guloseimas são distribuídas aos fiés, que acreditam que os docinhos são abençoados. Esta característica da religiosidade luso-brasileira, relacionada com um elevado grau de intimidade entre o santo e o fiel não é algo novo. Trata-se de um tema bastante explorado por diferentes autores brasileiros, como, por exemplo, Gilberto Freyre em sua obra clássica, Casa Grande Senzala. Segundo Freyre (2003), essa característica de intimidade é fruto do contacto do catolicismo ibérico com o islamismo:

Impossivel conceber-se um cristianismo português ou luso-brasileiro sem essa intimidade entre o devoto e o santo. Com Santo Antônio chega a haver semicerimônias obscenas. E com a imagem de São Gonçalo jogava-se peteca em festas de igreja dos tempos coloniais. Em Portugal, como no Brasil, enfeitam-se de tetéias, de jóias, de braceletes, de brincos, de coroas de ouro e diamante as imagens das virgens queridas ou dos Meninos-Deus como se fossem pessoas da familia. Dão-se-Ihes atributos humanos de rei, de rainha, de pai, de mãe, de filho, de namorado. Liga-se cada um deles a uma fase da vida doméstica e íntima. Nenhum resultado mais interessante dos muitos séculos do contacto do cristianismo com a religião do profeta - contacto que tantas vezes se aguçou, em asperezas de rivalidade - que o caráter militar tomado por alguns santos no cristianismo português e mais tarde no Brasil. (Freyre, 2003: 303 e 304)

A intimidade entre a devoção e a fé também pode ser observada na continuidade do relato de "Biló", transcrito pela pesquisadora Renata Araújo (2004), quando expõe como entende suas atividades e empenho na realização das festividades:

Então, é isso que eu sinto que Ela quer a festa, o dia que Ela não quiser... é uma vez só. É, ué! Então, é por isso que eu mexo na festa, porque eu sei que Ela quer. O que eu posso fazer pra Ela, eu mimo isso aí. Eu mimo. Porque a gente faz porque Ela tá fazendo pra nós. Trabalho mesmo. Trabalho mesmo! Pra festa eu trabalho mesmo. Então, é por isso que nós trabalha. (Araújo e Mahfoud, 2004: 37)

$O$ ato de enfeitar e vestir as imagens relatado por Freyre (2003) também pode ser observado como uma tradição associada à festa de Nossa Senhora de Nazaré de Morro Vermelho, aparecendo relatada na reportagem da Revista Círios da edição de 2016:

Outra tradição da Festa de Nossa Senhora de Nazaré também já demanda mais de três séculos: diversas famílias de moradores e de romeiros doam à igreja vestidos ricamente adornados para uso, durante as festividades, pelo menino Jesus, 
Fabrino, Raphael (2020). A ampliação do conceito de Patrimonio Cultural e o caso da Igreja de Nossa Senhora de Nazaré, de Morro Vermelho. In Alice Duarte (ed.), Seminários DEP/FLUP vol. 1. Porto: Universidade do Porto, Faculdade de Letras/DCTP, 192-215. https://doi.org/10.21747/9789898969682/seminariosv1a9

que fica nos braços da imagem da padroeira, sendo as vestes substituídas várias vezes ao dia. Depois do uso pelo menino Jesus, os vestidos das mais diversas cores e tecidos são em geral devolvidos aos doadores, que os guardam como relíquias. Outras são peças de promessas e graças alcançadas, que possuem emocionantes histórias de devotos que pela fé conseguiram ter seus pedidos atendidos. Algumas peças estão sendo recolhidas pela organização da festa, que pretende colocá-las futuramente no acervo de um museu dedicado a Nossa Senhora de Nazaré. (Revista Círios, 2016: 58)

Ao observarmos a dinâmica cultural dos festejos realizados em Morro Vermelho, com as suas inúmeras manifestações e expressões culturais centradas na figura de Nossa Senhora de Nazaré e na sua Igreja, percebemos a co-presença de mais valores culturais e simbólicos associados a estes bens, o que certamente complementa e enriquece o tombamento federal realizado. No entanto, apenas em 2009 a Festa de Nossa Senhora de Nazaré e sua Cavalhada foram reconhecidas como Património Cultural Imaterial pela legislação municipal de Caeté. Esse registro, que garante um subsídio anual para a manutenção da celebração, alarga o âmbito da salvaguarda patrimonial, mas também evidencia o reconhecimento e inserção destas práticas culturais num outro universo discursivo que, do ponto de vista das políticas públicas para a preservação do património cultural, pouco se relaciona com os aspetos ou dimensões valorizados pelo tombamento de 1950. Essa falta de articulação entre os diversos instrumentos legais e as políticas públicas pode ocasionar dificuldades e conflitos na preservação efetiva dos elementos culturais significativos da celebração, uma vez que os diversos instrumentos pretendem salvaguardar diferentes aspetos de um mesmo "lugar", podendo isso acarretar conflito entre si. A dissociação entre os instrumentos legais que buscam salvaguardar as expressões e práticas culturais num sentido mais âmplo e dinâmico, em relação aos mecanismos de proteção que tutelam o chamado "património material" pode originar incoerências, já que o foco das intervenções é distinto. Pode-se assim, incorrer em recontextualizações artificiais e arbitrárias, o que, certamente, causa um empobrecimento significativo dos valores que se pretendem proteger. Esses conflitos podem tornar-se ainda mais flagrantes quando os usos e práticas culturais associadas a um determinado bem patrimonial colidem com as normas e procedimentos da conservação e preservação, como acontece no caso da imagem do Senhor dos Passos da Igreja de Nossa Senhora de Nazaré. 
Fabrino, Raphael (2020). A ampliação do conceito de Patrimonio Cultural e o caso da Igreja de Nossa Senhora de Nazaré, de Morro Vermelho. In Alice Duarte (ed.), Seminários DEP/FLUP vol. 1. Porto: Universidade do Porto, Faculdade de Letras/DCTP, 192-215. https://doi.org/10.21747/9789898969682/seminariosv1a9

\subsection{O Ritual do Banho do Nosso Senhor dos Passos em Morro Vermelho}

Como o campo do património, as disciplinas que lhe dão suporte foram-se desenvolvendo desde a viragem do século XVIII para o XIX e, desde aí, sofrerem diversos ajustamentos. Atualmente, a conservação e preservação de prédios históricos e obras de arte abarcam um grande conjunto de práticas e disciplinas regidas por normas e critérios aceites mundialmente. Em algumas circunstâncias, como no caso dos bens móveis de cunho devocional ainda presentes em templos, o processo de patrimonialização pode promover mudanças significativas no estatuto do objeto em causa ao the conferir novos valores que pouco ou nada se relacionam com o seu cotidiano. Ao conferir esta nova distinção, o processo de patrimonialização insere o objeto num novo contexto de regras e práticas de preservação que podem entrar em conflito com o seu uso costumeiro, ou mesmo ameaçar a sua segurança, por exemplo, por passar também a ser valorizado no mercado de arte.

No Brasil, a partir da segunda metade do século XX, como forma de preservar os acervos de arte sacra ainda presentes em muitos templos das capitais e do interior frequentemente vítimas de furtos e descaminhos - são estimuladas as políticas públicas de criação e/ou recolhimento de inúmeros bens em museus. Foi durante esse período

que foram fundados os principais museus de Arte Sacra no Brasil, como os de Parati, São Paulo, Bahia, Pernambuco, São João Del Rei, São Cristóvão e muitos outros. Para compor os respetivos acervos, foram recolhidas imagens, paramentos e objetos de distintas igrejas, capelas, conventos, mosteiros e oratórios, particulares e de rua. Nestes casos, pode-se perceber que os aspectos históricos e artísticos valorizados no processo de patrimonialização se sobrepuseram aos valores devocionais, ritualísticos e afetivos que ligavam o bem à sua comunidade de origem. Da mesma forma, o tratamento dispensado a um objeto museológico de arte sacra difere muito das práticas e usos cotidianos que justificam sua presença numa igreja ou capela. Partindo do pressuposto de que todo o objeto dentro de uma igreja cumpre, ou já cumpriu, uma função religiosa ou liturgica específica, pode-se considerar que uma imagem sacra presente num altar se configura como um bem em uso, cumprindo a função para a qual foi concebida e sendo um importante elo identitário entre os moradores da comunidade e os seus 
Fabrino, Raphael (2020). A ampliação do conceito de Patrimonio Cultural e o caso da Igreja de Nossa Senhora de Nazaré, de Morro Vermelho. In Alice Duarte (ed.), Seminários DEP/FLUP vol. 1. Porto: Universidade do Porto, Faculdade de Letras/DCTP, 192-215. https://doi.org/10.21747/9789898969682/seminariosv1a9

antepassados. Não é incomum encontrarmos várias gerações de uma mesma família como organizadores de festejos, de procissões e sendo devotos de uma imagem específica, a qual também pode possuir valor histórico, artístico e econômico. Como se referiu, segundo a legislação nacional brasileira de preservação do património cultural, mesmo não estando num museu, todos os objetos presentes na igreja à época de seu tombamento são considerados igualmente tombados, o que lhes impõe um conjunto de regras que restringe a sua conservação, circulação, venda e utilização.

A fim de problematizar as questões relacionadas com a legislação em vigor (no Brasil, mas não só) e o uso de objetos tombados em práticas e manifestações tradicionais, assim como enfatizar a necessidade de uma abordagem mais integral dos aspectos constituintes de um determinado património cultural, a análise do Ritual do Banho do Nosso Senhor dos Passos, da Igreja Matriz de Nossa Senhora de Nazaré, em Morro Vermelho, mostra-se particularmente elucidativa. Pela legislação brasileira, a imagem do Senhor dos Passos pertencente à Igreja também é considerada um bem tombado, por força da resolução do Conselho Consultivo da SPHAN, de 13 de agosto de 1985. Em sua ficha de inventário, elaborada em 1987, estão ausentes informações referentes à utilização do bem em contexto ritual.

No início do ano de 2013, uma equipa multidisciplinar da Gerência de Patrimônio Imaterial, do Instituto Estadual do Património Histórico e Artístico, de Minas Gerais, esteve na comunidade de Morro Vermelho a fim de documentar o Ritual do Banho de Cachaça da imagem do Senhor dos Passos. Na documentação gerada, esse ritual foi classificado como proveniente do catolicismo de cunho popular e as informações foram consolidadas numa ficha de inventário de Celebrações e Ritos do Património Cultural Imaterial de Minas Gerais. Socorrendo-se de uma metodologia diferente da do inventário de obras de arte utilizada em 1987, o trabalho realizado pelo Instituto Estadual em 2013 enfatiza os aspetos práticos, simbólicos e sociais relacionados com o uso do bem no referido ritual, sem apresentar preocupação específica com a sua materialidade. 
Fabrino, Raphael (2020). A ampliação do conceito de Patrimonio Cultural e o caso da Igreja de Nossa Senhora de Nazaré, de Morro Vermelho. In Alice Duarte (ed.), Seminários DEP/FLUP vol. 1. Porto: Universidade do Porto, Faculdade de Letras/DCTP, 192-215. https://doi.org/10.21747/9789898969682/seminariosv1a9
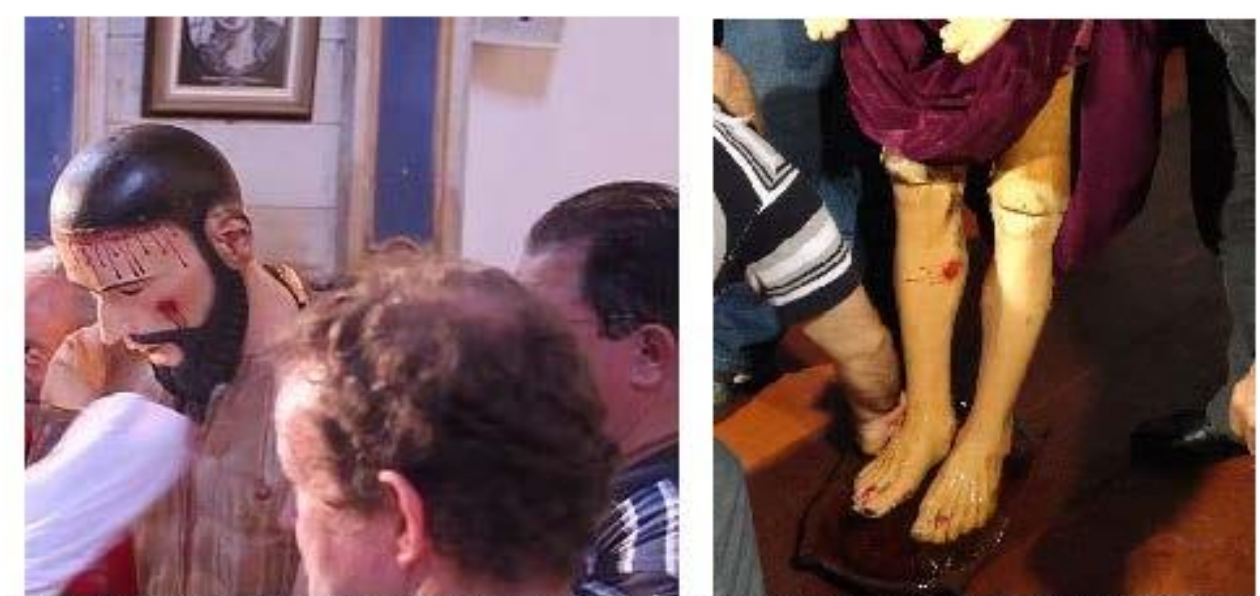

Fig 4 e 5 - Ritual do Banho de Cachaça sobre a imagem do Senhor dos Passos da Igreja de N. S. da Nazaré

Segundo as informações levantadas, o ritual ocorre sempre na quartafeira de cinzas, o primeiro dia da quaresma. Essa prática é atribuída pelos moradores locais aos seus antepassados, como forma de evitar o ataque de insetos e mofo sobre a imagem, utilizando a cachaça com essa finalidade. Sob a justificativa de que a imagem se manteve preservada durante todo esse tempo, o rito teve continuidade. Chama aqui a atenção o facto de, na mesma Igreja, existirem outras imagens que não passam pelo mesmo processo de "conservação", sendo o descrito, em princípio, apenas executado na imagem do Senhor dos Passos.

Outro ponto que chamou a atenção dos técnicos do IEPHA-MG foi o facto de, apesar dos praticantes relatarem que não existe nenhuma preparação formal no que se refere às prescrições e rezas para o Banho de Cachaça, a equipa registou alguns procedimentos específicos na preparação do espaço para a realização do ritual: as garrafas com a cachaça que serão utilizadas ficam dispostas na mesa do altar, todo ele decorado na cor roxa, que simboliza liturgicamente a quaresma; as roupas usadas pela imagem (túnica, camisa e ceroula) são retiradas, havendo outras devidamente limpas, passadas e separadas para serem vestidas após o Banho. Segundo o relato dos pesquisadores:

É preciso no mínimo de quatro pessoas para conseguir retirar a imagem de Nosso Senhor dos Passos do altar para o banho, pois a imagem pesa cerca de 30 quilos. O banho ocorre ao lado do retábulo do evangelho onde a imagem fica a maior parte do ano, quando não está no andor durante a Quaresma. O número de pessoas que auxiliam no banho e preparativos pode variar de acordo com o ano, todavia alguns participantes são fixos, como é o caso de Nildo, Biló, seu irmão, Antônio Lopes (Tõezinho) e Antônio Itamar Vieira (Gelatina), cunhado de Tõezinho. Os observadores 
Fabrino, Raphael (2020). A ampliação do conceito de Patrimonio Cultural e o caso da Igreja de Nossa Senhora de Nazaré, de Morro Vermelho. In Alice Duarte (ed.), Seminários DEP/FLUP vol. 1. Porto: Universidade do Porto, Faculdade de Letras/DCTP, 192-215. https://doi.org/10.21747/9789898969682/seminariosv1a9

da cerimônia presentes no adro da igreja também podem ser convidados a participar. Um detalhe significativo é que todos os presentes no rito, seja como oficiantes do banho, ou como observadores, são homens. Sobre tal fato, Nildo esclarece: "(...) ele (NSP) é um homem também, né? E a gente é, e tira a roupa dele, né, então, não é legal uma mulher tá vendo um homem pelado, né, apesar dele não ter sexo, né, então, nós respeitamos essa tradição desde o princípio. (8:22)

Depois que a imagem é retirada do retábulo e despida, é posicionada uma gamela aos seus pés, usada para recolher o líquido que escorre. o banho tem início com o despejo de cachaça na gamela para as primeiras limpezas, feitas nos pés e mãos. Depois do banho, Nosso Senhor dos Passos é enxugado cuidadosamente com uma toalha e depois vestido com novas roupas. Em seguida a imagem é posicionada em cima de um andor que está próximo ao altar-mor. A imagem fica ajoelhada sobre o joelho esquerdo e, após ser amarrado em cordas e fixado em estacas, está pronto para receber sua cruz, apoiada sobre o ombro esquerdo. (Ficha de Inventário do Património Cultural Imaterial de Minas Gerais Celebrações e Ritos, $2013: 2$ e 3)

Ainda no que se refere à celebração observada em 2013, os técnicos do IEPHAMG destacam que um dos devotos presentes foi convidado a iniciar o ritual, com o voto e esperança de receber uma graça para sua enfermidade, pois encontrava-se acometido por doença grave e, à medida que molhava cuidadosamente a imagem, também molhava a própria cabeça com o líquido acumulado na gamela abaixo. Segundo os praticantes, o líquido que passou pela imagem, possui agora propriedades medicinais; é recolhido e guardado para ser usado durante o resto do ano, podendo ser utilizado para curar o corpo e a alma daqueles que têm fé:

Durante todo o processo, a cachaça é retirada da gamela com uma pequena cabaça cortada ao meio e compartilhada entre os participantes. Todo o corpo da imagem é seco por panos. Novas vestes são colocadas. O manto da imagem é agora na cor roxa Na mesa localizada do lado da epístola foram colocadas as garrafas vazias utilizadas no banho. Outras duas não utilizadas foram derramadas na gamela, colocada na mesa, que continha o líquido benzido no rito e, desse modo, o líquido ali posto depois do banho é benzido pelo contato com o líquido já bento. A cachaça abençoada estará à disposição de fiéis após o rito, para ser bebida na hora, passada no rosto ou cabeça, ou, ainda, levada para casa. (Ficha de Inventário do Património Cultual Imaterial de Minas Gerais Celebrações e Ritos, 2013: 3)

Também foi registado um aumento do número de pessoas interessadas em acompanhar o ritual, dentro e fora da Igreja. Segundo os participantes, o ritual foi ganhando visibilidade nos últimos anos em virtude de sua divulgação pelos meios de comunicação social locais e pelas graças atribuídas ao uso da cachaça utilizada no Banho. Alguns relatos quanto à transmissão dos conhecimentos relacionados com a prática do ritual, também foram transcritos: 
Fabrino, Raphael (2020). A ampliação do conceito de Patrimonio Cultural e o caso da Igreja de Nossa Senhora de Nazaré, de Morro Vermelho. In Alice Duarte (ed.), Seminários DEP/FLUP vol. 1. Porto: Universidade do Porto, Faculdade de Letras/DCTP, 192-215. https://doi.org/10.21747/9789898969682/seminariosv1a9

Nildo: [entrevista do dia 06 de fevereiro de 2013] É, quem me entregou essa incumbência foi o pai dele e mais uns outros velhos, né, ele é mais novo. Então, quem me entregou foi o pai dele, então, quando o pai dele foi me passando eu já tava com dez, com idade, ele foi me, eu ajudava, depois dos dezoito ano...eu ajudava, mais, quando ele ficou bem mais velho e a doença já começou à chegá, ele começou falá ó como que eu tinha que fazê, passando informação da imagem pra mim, ensinando a gente a fazê alguma coisa como aquele nó de, da corda fica no pescoço dele. Aonde que a gente não devia de mexê com mais cuidado que as vistas dele a gente não podia...é, é, é com muito jeito senão ela podia afundá pra dentro e, e nós não sabíamos como que nós ia fazê, né, então ele foi me explicando essas coisa, ele foi deixando pra gente fazê mesmo! Ele só mandando, né. (5:23).

Gelatina [entrevista do dia 13 de fevereiro de 2013]: sempre (?) eu tenho pouco tempo, eu tô com 26 anos que eu participo através do pai de Biló e pai de Tiãozinho que é meu sogro, os dois são irmãos, entendeu? O meu sogro, ele me convidou, ele e um outro irmão dele, Aristide, que participava me convidou, quando eu comecei a namorar com a filha dele, pra participá. Aí eu venho participando. Desde que eu participo sempre foi feito dessa maneira. Aí, o porquê, eu acredito que seja, que fica ali, não deixa de entrá uma poeira, sujá uma teia de aranha e tudo. Então, nesse dia, pra fazê uma higienização na imagem, usa-se a cachaça porque além dela, o álcool, né, o álcool não seja corrosivo, ele mantém contra os cupins, contra as outras coisas que vai, que pode danificá a imagem. Então, desde que eu comecei participando já era dessa maneira. (Ficha de Inventário do Património Cultural Imaterial de Minas Gerais Celebrações e Ritos, 2013: 5 e 6)

Sobre as propriedades medicinais e terapêuticas da cachaça utilizada no Banho, os participantes exaltam o seu potencial sagrado de cura e, ocasionalmente, a graça alcançada por alguém que a usou ganha o estatuto de milagre, por parte dos oficiantes do rito e da comunidade de Morro Vermelho. Essa fama também fez crescer a sua demanda na região, como relata um dos praticantes:

Biló [entrevista do dia 06 de fevereiro de 2013]: aí então, é, e a gente usa também uma, nós tem uma gamela, uma bacia pra podê a cachaça vim a pará ali. $E$ essa cachaça ficou, e esse trem pra rodô foi por conta mais é, por conta da, do milagre sabe? Que os outros passava a cachaça, eles pôs pra rodá pra turma: " - usei uma cachaça lá dum santo lá no Morro Vermelho, passei e curô. - Uai, mas que cachaça é essa? - É do Senhor dos Passos". Aí, juntô, os outros andô procurando, nós falô: " aah, mas é só quarta-feira de cinzas. - Ah, mas não tem nem um bucadinho não?" As vezes, o Nildo guardava. (?) "o Nildo deve tê". A gente levava, curava e ficô! E nisso foi crescendo e crescendo...agora que a gente também nem lembra, como é que isso começô que isso vem desde os antigo. Eu, quando eu lembro quando o véio tava, eu tava menino, papai mexia com isso. Na época deles aí, a gente vinha e ficava no buraco da fechadura e o trem foi até, tomô idade que ele fala: "-agora cê pode...". Esperô dezoito ano pra mim podê ajudá eles a mexê com o Senhor dos Passos. E nisso, a cachaça foi fazendo milagre por aí e cresceu esse trem aí. E tanto que já tem gente encomendando: " - cês guarda uma cachaça pra mim! (3: 46). (Ficha de Inventário do Património Cultual Imaterial de Minas Gerais Celebrações e Ritos, 2013: 6) 
Fabrino, Raphael (2020). A ampliação do conceito de Patrimonio Cultural e o caso da Igreja de Nossa Senhora de Nazaré, de Morro Vermelho. In Alice Duarte (ed.), Seminários DEP/FLUP vol. 1. Porto: Universidade do Porto, Faculdade de Letras/DCTP, 192-215. https://doi.org/10.21747/9789898969682/seminariosv1a9

Segundo os participantes, seu potencial de cura é associado à melhoria e alívio de dores de cabeça e garganta, bem como à cura do alcoolismo. Em relação à continuidade do ritual, os técnicos do IEPHA relatam a grande satisfação dos participantes com o aumento da visibilidade e das pessoas que acompanham o rito. Sobre as possibilidades de continuidade do ritual e transmissão do conhecimento às gerações futuras, os participantes relataram que o aprendizado obedece à tradição histórica, ou seja, o aprendiz deve ter no mínimo 18 anos e ser incorporado pelos participantes mais antigos. A "incumbência" da "responsabilidade" é entregue pelos "antigos" aos atuais oficiantes. Conforme registado no depoimento de Biló:

Sempre a gente já põe um mais novo assim, que já, a gente tem que vê quem tá querendo ajudá a gente já põe pra podê, já, aí, que a gente num sabe, uma hora falta um, né.". "(...) eu acho que tem, mas, né, sei lá. A gente tem que enfiando um no meio, né, pra podê, tanto que nós já, tem um novo aí que nós criô. Nós tem um de fora que acabo ajudando nós também. Belo Horizonte. Cê vê, vem toda quarta-feira de cinzas ajudá a mexê com Nosso Senhor dos Passos (...). (Ficha de Inventário do Património Cultural Imaterial de Minas Gerais Celebrações e Ritos, 2013: 9)

Por fim, os técnicos do IEPHA-MG, seguindo as recomendações da Convenção para Salvaguarda do Patrimônio Cultural Imaterial no que tange à participação da comunidade, ratificam as medidas de salvaguarda apontadas pelos oficiantes, como a valorização das tradições do distrito por meio da escola de forma a desenvolver o interesse na participação das manifestações tradicionais da região. Outros pontos destacados são a manutenção deste rito no seio da comunidade e o impedimento da ingerência de agentes externos à comunidade, sejam eles dos meios de comunicação social ou do poder público.

\section{Conclusão}

Ao examinarmos o caso da Igreja Matriz de Nossa Senhora de Nazaré e as manifestações a ela associadas sob as premissas de um conceito integrado de património e de uma noção antropológica de cultura é possível perceber que diversas práticas e manifestações culturais de grande relevância para a comunidade respetiva não foram abarcadas pelas políticas patrimoniais do século XX. Nesse sentido, também fica evidente que as funções atribuídas ao património cultural se modificaram ao longo 
Fabrino, Raphael (2020). A ampliação do conceito de Patrimonio Cultural e o caso da Igreja de Nossa Senhora de Nazaré, de Morro Vermelho. In Alice Duarte (ed.), Seminários DEP/FLUP vol. 1. Porto: Universidade do Porto, Faculdade de Letras/DCTP, 192-215. https://doi.org/10.21747/9789898969682/seminariosv1a9

do tempo. Outrora entendido sobretudo como referência artística ou arquitetónica e testemunho histórico, o conceito de património deixa atualmente de contemplar apenas os vestígios materiais remanescentes, para compreender também as manifestações e expressões culturais vivas e pulsantes que lhes estejam associadas.

Para que isso efetivamente ocorra, os antigos parâmetros, regras e práticas institucionais devem ser revistos e adaptados à luz dos novos tempos. Certamente, o caso do Ritual do Banho do Nosso Senhor dos Passos não encontra respaldo nos preceitos das disciplinas envolvidas na conservação e restauro de obras de arte, pois não existem estudos que relacionem a preservação da madeira contra insetos por meio do uso da cachaça. Mas, de igual forma, orientados pelos atuais parâmetros de concepção do património cultural, será inconcebível cercear o ritual a fim de se preservar apenas os aspetos materiais do bem, interferindo nos valores sociais, simbólicos e mágicos que lhe estão associados. Esses riscos seriam dirimidos pela adoção de práticas e políticas públicas patrimoniais mais integradas, que levem em conta todos os valores culturais de um bem. Além de uma nova abordagem, é preciso incluir os novos atores no bojo do processo decisório, o que nem sempre é fácil. Caberá às instituições e às disciplinas que constituem o campo do património cultural atentar para as novas concepções vigentes, buscando compreender que a unicidade do novo conceito não opõe material e imaterial, erudito e popular ou tradição e mudança, mas exige que o processo de aferição de valores culturais e patrimoniais seja realizado de forma integrada, ampla, democrática e participativa.

Nas palavras do antropólogo José Reginaldo Gonçalves (2003): “o património é usado não apenas para simbolizar, representar ou comunicar: é bom para agir". Ou seja, a sua existência não se restringe à representação de valores e ideias abstratas em bens para serem contemplados; ele constrói e forma as pessoas. Os sentidos do património podem ser atribuídos a suportes tangíveis ou intangíveis, materiais ou não, a artefatos ou a manifestações orais. Podem estar nos objetos, assim como nas práticas, nos espaços físicos e nos lugares socialmente construídos. Nesse sentido, deve-se somar ao conhecimento técnico, artístico e científico produzido pelas instituições públicas e pelos especialistas do património, as narrativas de memórias, identidades e afetos produzidos e repartidos entre os membros das comunidades que convivem há gerações com um 
Fabrino, Raphael (2020). A ampliação do conceito de Patrimonio Cultural e o caso da Igreja de Nossa Senhora de Nazaré, de Morro Vermelho. In Alice Duarte (ed.), Seminários DEP/FLUP vol. 1. Porto: Universidade do Porto, Faculdade de Letras/DCTP, 192-215. https://doi.org/10.21747/9789898969682/seminariosv1a9

determinado bem cultural. Por mais simples e óbvio que possa parecer, trazer novos atores, opiniões e olhares para um ambiente dominado pelo tecnicismo não é uma tarefa fácil, mas quando esses universos se entrecruzam, é possível perceber toda a potência do património cultural.

\section{Referências Bibliográficas}

Abreu, Regina (2015). Patrimonialização das diferenças e os novos sujeitos de direito coletivo no Brasil. In Cécile Tardy, Vera Dobel (Orgs), Memória e Novos Patrimônios. Marselha: OpenEdition Press, v. 1, p. 67-93.

Abreu, Regina (2014). Dez Anos da Convenção do Patrimônio Imaterial: Ressonâncias, Apropriações, Vigilâncias. E-Cadernos Centro de Estudos Sociais da Universidade de Coimbra, v. 21, p. 5-15. Disponível em: http://www.reginaabreu.com/site/index.php/artigos1/item/115-2014-dezanos-da-convencao-do-patrimônio-imaterial-ressonancias-apropriacoesvigilancias [Acesso em 28/03/2019].

Araújo, R.A. \& Mahfoud, M. (2004). A devoção a Nossa Senhora de Nazaré a partir da elaboração da experiência ontológica de moradores de uma comunidade tradicional. Revista Memorandum, Memória e História em Psicologia, n. 6. Disponível em: http://www.fafich.ufmg.br/ memorandum/artigos06/aramahfoud01.htm Acesso em: 24/04/2019

Duarte, Alice (2010). O desafio de não ficarmos pela preservação do patrimônio cultural imaterial, Actas do I Seminário de Investigação em Museologia dos Países de Língua Portuguesa e Espanhola, vol. 1, p. 41-61.

Freyre, Gilberto (2003). Casa-Grande e Senzala: Formação da família brasileira sob o regime da economia patriarcal (48a ed). São Paulo: Global. Disponível em: https://gruponsepr.files.wordpress.com/2016/10/freyre gilberto casagrande senzala.pdf [Acesso em: 04/05/2019]

Gonçalves, José Reginaldo (2003). O Patrimônio como Categoria de Pensamento. In Regina Abreu \& Mário Chagas (Orgs.), Memória e Patrimônio: ensaios contemporâneos. Rio de Janeiro: DP\&A editora, p. 21-29.

Sant'Anna, Márcia (2015). Preservação como prática: sujeitos, objetos, concepções e instrumentos. In Maria Beatriz Rezende, Bettina Grieco, Luciano Teixeira \& 
Fabrino, Raphael (2020). A ampliação do conceito de Patrimonio Cultural e o caso da Igreja de Nossa Senhora de Nazaré, de Morro Vermelho. In Alice Duarte (ed.), Seminários DEP/FLUP vol. 1. Porto: Universidade do Porto, Faculdade de Letras/DCTP, 192-215. https://doi.org/10.21747/9789898969682/seminariosv1a9

Analucia Thompson (orgs.), Dicionário IPHAN de Patrimônio Cultural. Rio de Janeiro: IPHAN, p. 1- 36.

Sherkin, Samantha (2001). A Historical Study on the Preparation of the 1989 Recommendation on the Safeguarding of Traditional Culture and Folklore. In Peter Seitel (ed.), Safeguarding Traditional Cultures. A Global Assessment. Washington, DC: Center for Folklife and Cultural Heritage, Smithsonian Institution, p. 1-17.

Revista Círio de Morro Vermelho [s.a.] (2007). MG In Círios de Nazaré. Belém do Pará: Editora Círios SS Ltda. Disponível em: https://issuu.com/revistaamazonia/docs/cirios2007 [Acesso em: 03/05/2019]

Revista Círio de Morro Vermelho [s.a.] (2008). MG In Círios de Nazaré. Belém do Pará: Editora Círios SS Ltda. Disponível em: https://issuu.com/revistaamazonia/docs/cirios2008 [Acesso em: 03/05/2019]

Revista Círio de Morro Vermelho [s.a.] (2009). MG In Círios de Nazaré. Belém do Pará: Editora Círios SS Ltda. Disponível em: https://issuu.com/revistaamazonia/docs/cirios2009 [Acesso em: 03/05/2019]

Revista Círio de Morro Vermelho [s.a.] (2010). MG In Círios de Nazaré. Belém do Pará: Editora Círios SS Ltda. Disponível em: https://issuu.com/revistaamazonia/docs/cirios2010 [Acesso em: 03/05/2019]

Revista Círio de Morro Vermelho [s.a.] (2011). MG In Círios de Nazaré. Belém do Pará: Editora Círios SS Ltda. Disponível em: https://issuu.com/revistaamazonia/docs/cirios2011 [Acesso em: 03/05/2019]

Revista Círio de Morro Vermelho [s.a.] (2012). MG In Círios de Nazaré. Belém do Pará: Editora Círios SS Ltda. Disponível em: https://issuu.com/revistaamazonia/docs/cirios2012 [Acesso em: 03/05/2019]

Revista Círio de Morro Vermelho [s.a.] (2014). MG In Círios de Nazaré. Belém do Pará: Editora Círios SS Ltda. 2014. Disponível em: https://issuu.com/revistaamazonia/docs/cirios2014 [Acesso em: 03/05/2019]

Revista Círio de Morro Vermelho [s.a.] (2015). MG In Círios de Nazaré. Belém do Pará: Editora Círios SS Ltda. Disponível em: https://issuu.com/revistaamazonia/docs/cirios2015 [Acesso em: 03/05/2019]

Revista Círio de Morro Vermelho [s.a.] (2016). MG In Círios de Nazaré. Belém do Pará: Editora Círios LS Ltda. Disponível em: https://issuu.com/revistaamazonia/docs/cirios2016 [Acesso em: 03/05/2019]

Revista Círio de Morro Vermelho [s.a.] (2017). MG In Círios de Nazaré. Belém do Pará: Editora Círios SS Ltda. Disponível em: https://issuu.com/revistaamazonia/docs/cirios2017 [Acesso em: 03/05/2019] 
Fabrino, Raphael (2020). A ampliação do conceito de Patrimonio Cultural e o caso da Igreja de Nossa Senhora de Nazaré, de Morro Vermelho. In Alice Duarte (ed.), Seminários DEP/FLUP vol. 1. Porto: Universidade do Porto, Faculdade de Letras/DCTP, 192-215. https://doi.org/10.21747/9789898969682/seminariosv1a9

\section{Documentos:}

Declaração do México, 1982.

Recomendação sobre a Salvaguarda da Cultura Trradicional e do Folclore, 1989.

Carta de Nara, 1994.

Convenção para a Salvaguarda do Património Cultural Imaterial, 2003.

Processo de Tombamento da Igreja Matriz de Nossa Senhora de Nazaré, IPHAN № 0397-T, 1950 - Brasil.

Decreto-ei no 25 DE 1937 - IPHAN - Brasil.

Resoluçãoo do Conselho Consultivo da SPHAN, de 13 de agosto de 1985 - IPHAN - Brasil. Ficha de Inventário de Bens Móveis e Integrados do IPHAN - 1987 - Brasil.

Ficha de Inventário do Património Cultural Imaterial de Minas Gerais Celebrações e Ritos 2013 - IEPHA - Brasil. 